\section{Folia Phoniatrica \\ et Logopaedica}

Chelas, E.N. 179

Christaki, V. 179

Christodoulou, M. 187

Constantinidou, F. 187

Efstratiadou, E.A. 179

Ferré, P. 199

Fonseca, R.P. 199
Heikkinen, P. 169

Hilari, K. 179

Ignatiou, M. 179

Joanette, Y. 199

Klippi, A. 169
Laine, M. 169

Lehečková, H. 165

Papathanasiou, I. 179

Paquier, P.F. 163

Prokopiou, J. 187

Sellman, J. 169

Ska, B. 199

\title{
Subject Index Vol. 64, No. 4, 2012
}

Aging 187

Aphasia 169

- therapy 169

Assessment of aphasia 165

Best practice 169

Clinical decision-making 169

- practices 169

Clusters 199

Cognition 187

Communication 199

Czech Republic 165
Education 187

Executive functioning 187

Greece 179

Greek 187

Guidelines 169

Health-related quality of life 179

Language 187

Lexical access 187

Lexicon 187

Right brain damage 199
Semantic memory 187

Speech and language therapy 169 Stroke 179, 199

- and Aphasia Quality of Life Scale 179

Treatment of aphasia 165

Vocabulary 187

\section{KARGER}

๑) 2012 S. Karger AG, Basel 